\title{
NILAI-NILAI FIQIH DALAM MEMBANGUN \\ KARAKTER PESERTA DIDIK DI SD/MI \\ Nasri
}

\section{STIT Palapa Nusantara Lombok-NTB}

Email: nasriazkia190@gmail.com

\begin{abstract}
The search for thoughts about the education of fiqh, where fiqh inquiry has in essence has a great significance for the continuity of education in the modern era as nowadays. Besides, this research also to be used as an information material for the community of the importance of the meaning of fiqh education for life, especially in order facing modern life that has tendency of waning of values or norms of law in order of life of society also as material of information and documentation for planner and educational designer, Values in Islam contain two categories of meaning seen from normative aspect, that is good and bad. The spiritual values of jurisprudence have a close connection with a day's amaliah especially concerning worship to God. The value of jurisprudence is also a spirit (spirit) to go to the pleasure of Allah. Spiritual fiqih were extracted from two ways namely; Through faith and piety and through worship Building the Islamic character departs from two ways closely related to the basic of akhlaki. The concept of pious faith is the foundation of all activities while the concept of worship centers on an important basic principle that man was created as the holder of the mandate of Allah Almighty. who carries the treatise and exercises His Sharia.
\end{abstract}

Kata Kunci : Nilai-Nilai Fiqih, Karakter Peserta Didik

\section{PENDAHULUAN}

Pendidikan adalah suatu usaha sadar dan sistematis dalam mengembangkan potensi peserta didik ${ }^{1}$. Pendidikan adalah juga suatu usaha masyarakat dan bangsa dalam mempersiapkan generasi mudanya bagi keberlangsungan kehidupan masyarakat dan bangsa yang lebih baik di masa depan. Keberlangsungan itu ditandai oleh pewarisan budaya dan

\footnotetext{
${ }^{1}$ Undang - undang No:20 Thn.2003 Tentang Sisdiknas
} 
karakter yang telah dimiliki masyarakat dan bangsa. Oleh karena itu, pendidikan adalah proses pewarisan budaya dan karakter bangsa bagi generasi muda dan juga proses pengembangan budaya dan karakter bangsa untuk peningkatan kualitas kehidupan masyarakat dan bangsa di masa mendatang. Dalam proses pendidikan budaya dan karakter bangsa, secara aktif peserta didik mengembangkan potensi dirinya, melakukan proses internalisasi, dan penghayatan nilai-nilai menjadi kepribadian mereka dalam bergaul di masyarakat, mengembangkan kehidupan masyarakat yang lebih sejahtera, serta mengembangkan kehidupan bangsa yang bermartabat.

Para pakar pendidikan sepakat bahwa fiqih bisa diformulasikan, dibina dan dikembangkan berdasarkan potensi dasar dan kebutuhan yang dimiliki manusia itu sendiri. Pendidikan fiqih bisa dilakukan di dalam keluarga, masyarakat dan di lembagalembagaípendidikan yang di bangun oleh lembaga swasta maupun pemerintah. Pendidikan fiqih bisa diformulasi dalam bentuk pembiasaan dan peniruan, teoritis dan praktis. Pendidikan fiqih mempunyai keunikan tersendiri dibanding dengan materi pelajaran lain yang diajarkan di lembaga pendidikan. Keunikan yang pertama; Ilmu ini berkaitan erat dengan 'ubudiyah seseorang. Fiqih mengajarkan cara beribadah lengkap dengan rukun dan syaratnya, tanpa mengetahui fiqih tidak sah amal seseorang. Keunikan kedua, Fiqih adalah ilmu yang bersifat dinamis bisa disesuaikan dengan perkembangan ilmu pengetahuan dan perkembangan zaman. Keunikan ketiga Fiqih dijadikan acauan dan pedoman hukum setiap menghadapi masalah dan sumber rujukan setiap konflik hukum .

Dalam konteks pandangan filosofis kependidikan, Islam juga memandang manusia sebagai makhluk yang memerlukan pendidikan dan merekayasa pendidikan, sehingga eksistensi manusia itu sendiri akan terjaga terus menerus dari generasi ke generasi berikutnya. Manusia sebagai makhluk yang dapat dididik, dapat dimafhumi dari firman Allah:

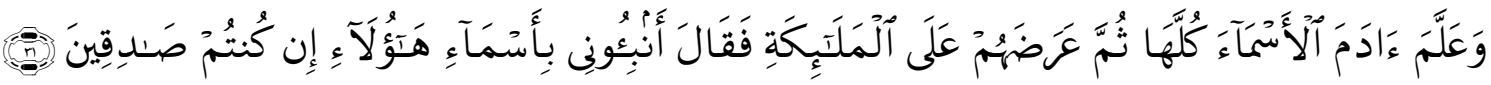

Dan Dia mengajarkan kepada Adam Nama-nama (benda-benda) seluruhnya, kemudian mengemukakannya kepada Para Malaikat lalu berfirman: "Sebutkanlah kepada-Ku nama benda-benda itu jika kamu mamang benar orang-orang yang benar!" 2

\footnotetext{
${ }^{2}$ Al-Qur'an (2) : 31
} 
Sementara manusia sebagai makhluk yang dapat mendidik, dapat difahami dari ayat al-Qur'an yang berkaitan dengan kisah Luqman dalam mendidik anaknya;

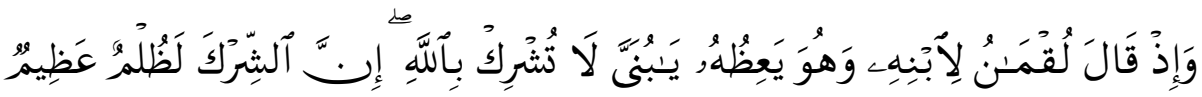

“ Dan (ingatlah) ketika Luqman berkata kepada anaknya, di waktu ia memberi pelajaran kepadanya: "Hai anakku, janganlah kamu mempersekutukan Allah, Sesungguhnya mempersekutukan (Allah) adalah benar-benar kezaliman yang besar'"3.

Manusia diwarisi dengan kecendrungan ke arah kebaikan atau kejahatan. Untuk memfilter itu semua tentunya manusia dituntut kesadaran tentang ilmu fiqih agar mengetahui mana yang positif dan mana yang negatif. Karena manusia diberikan akal, maka manusia diberikan alternatif untuk menjadi orang shlih, yang memiliki karakter baik, bernilai di lingkungan dan masyarakatnya. Dengan menerapkan nilai-nilai fiqih, karakter manusia dikontrol dalam hukum-hukum yang padu, sehingga manusia berbuat, sesuai dengan aturan yang berlaku dan bersifat mulia.

Karakter mulia berarti individu memiliki pengetahuan tentang potensi dirinya, yang ditandai dengan nilai-nilai seperti reflektif, percaya diri, rasional, logis, kritis, analitis, kreatif dan inovatif, mandiri, hidup sehat, bertanggung jawab, cinta ilmu, sabar, berhati-hati, rela berkorban, pemberani, dapat dipercaya, jujur, menepati janji, adil, rendah hati, malu berbuat salah, pemaaf, berhati lembut, setia, bekerja keras, tekun, ulet/gigih, teliti, berinisiatif, berpikir positif, disiplin, antisipatif, inisiatif, visioner, bersahaja, bersemangat, dinamis, hemat/efisien, menghargai waktu, pengabdian/dedikatif, pengendalian diri, produktif, ramah, cinta keindahan (estetis), sportif, tabah, terbuka, tertib. Individu juga memiliki kesadaran untuk berbuat yang terbaik atau unggul, dan individu juga mampu bertindak sesuai potensi dan kesadarannya tersebut. Karakteristik adalah realisasi perkembangan positif sebagai individu (intelektual, emosional, sosial, etika, dan perilaku).

Akan tetapi, karena manusia hidup dalam lingkungan sosial dan budaya tertentu, maka pengembangan karakter individu seseorang hanya dapat dilakukan dalam lingkungan sosial dan budaya yang bersangkutan. Artinya, pengembangan budaya dan karakter bangsa hanya dapat dilakukan dalam suatu proses pendidikan yang tidak melepaskan peserta didik dari lingkungan sosial,budaya masyarakat, dan budaya bangsa. Lingkungan sosial dan budaya bangsa adalah Agama; jadi pendidikan budaya dan karakter bangsa haruslah berdasarkan nilai-nilai agama. Dengan kata lain, mendidik budaya dan karakter bangsa adalah

\footnotetext{
${ }^{3}$ Al-Qur'an (31) :13
} 
mengembangkan nilai-nilai agama pada diri peserta didik melalui pendidikan hati, otak, dan fisik.

Penulis tertarik membahas nilai-nilai fiqih dalam membagun karakter peserta didik. UU No 20 Tahun 2003 Tentang Sistem Pendidikan Nasional pada Pasal 3, yang menyebutkan bahwa pendidikan nasional berfungsi mengembangkan kemampuan dan membentuk karakter serta peradaban bangsa yang bermartabat dalam rangka mencerdaskan kehidupan bangsa. Pendidikan nasional bertujuan untuk berkembangnya potensi peserta didik agar menjadi manusia yang beriman dan bertakwa kepada Tuhan Yang Maha Esa, berakhlak mulia, sehat, berilmu, cakap, kreatif, mandiri, dan menjadi warga negara yang demokratis serta bertanggung jawab.

\section{TUJUAN PENELITIAN}

Tujuan yang ingin dicapai dalam penelitian ini adalah untuk: Mengetahui tujuan pengajaran fiqih., Mengetahui nilai-nilai spiritual fiqih, Mengetahui strategi pembelajaran fiqih, Mengetahui fiqih membangun karakter Islami peserta didik.

\section{KEGUNAAN PENELITIAN}

Penelusuran terhadap pemikiran tentang pendidikan fiqih, pada hakekatnya memiliki signifikansi yang besar bagi kelangsungan pendidikan di era modern seperti sekarang ini. Karenanya hasil yang diperoleh dari aktifitas penelitian ini diharapkan memiliki kegunaan sebagai berikut: Pertama, Sebagai bahan informasi bagi masyarakat akan pentingnya arti pendidikan fiqih bagi kehidupan, terutama dalam rangka menghadapi kehidupan modern yang memiliki kecenderungan semakin memudarnya nilai-nilai atau norma-norma hukum dalam tata kehidupan bermasyarakat. Kedua, Sebagai bahan informasi dan dokumentasi bagi para planner dan designer pendidikan, pengamat dan praktisi pendidikan dalam rangka aktivitas merencanakan dan mengembangkan pendidikan di indonesia, khususnya pendidikan fiqih. Ketiga, Sebagai bahan kontribusi bagi upaya pengembangan dunia pendidikan Islam, terutama pendidikan fiqih dalam rangka memperkaya khazanah pemikiran yang berasal dari penelurusan terhadap para pemikir dan intelektual Islam.

\section{METODE PENELITIAN}

Penelitian ini berdasar atas kajian pustaka atau studi literatur. Kajian pustaka merupakan kewajiban dalam penelitian khususnya penelitian akademik yang bertujuan untuk mengembangkan aspek teoritis maupun aspek praktis. Kajian Pustaka juga 
merupakan suatu kegiatan yang tidak dapat dipisahkan dari suatu penelitian. Oleh karena itu pendekatan yang digunakan dalam penelitian ini adalah penelitian kepustakaan atau library research.

Dalam penelitian pustaka ini, kepustakaan yang digunakan ada kriteria; pertama, Relevansi, yaitu relevansi yang berkenaan dengan kecocokan antara variable-variabel yang diteliti dengan teori-teori yang dikemukakan. Kedua, Kelengkapan, adalah kelengkapan yang berkaitan dengan banyaknya kepustakaan yang dikaji atau dibaca. Ketiga, Kemutakhiran, sesuatu yang berkenan dengan demensi waktu kepustakaan yang digunakan. Pada penelitian ini penulis banyak menggunakan acuan kitab-kitab Arab klasik (kuno) mengingat kitab arab yang kuno lebih valid konteksnya daripada kitab yang baru terbit atau yang dicetak baru.

Data yang dikumpulkan terdapat dua jenis, yaitu data primer dan data sekunder. Data primer (primary source) merupakan sumber bahan yang ditulis oleh seseorang yang melihat, mengamati, mengalami atau mengerjakan sendiri. Bahan kepustakaan semacam ini dapat berupa; Bulletin , desertasi, laporan penelitaian, notulen rapat, hasil wawancara, autobiografi dan lain-lain. Data primer yang digunakan penulis adalah data tentang Fikih berbasis karakter seperti al-Ghunyah Imam al-Jailani, Ihya' 'Ulumuddin Imam al-Ghazali, Adab al-Dunya wa al-Ddin Imam al- Mawardi, Tanwirul Qulum oleh al-Kurdi dan 'Izzat alNashin, oleh Mustafa al-Ghulayini.

Sedang data sekunder ( secondary source) merupakan sumber bahan kajian lain yang dikemukakan orang atau pihak yang hadir pada saat terjadinya peristiwa atau tidak mengalami langsung peristiwa tersebut, bahan kepustakaan ini dapat berupa ensiklopedi, kamus, ringkasan, abstrak, dan lain-lain. Data pelengkap yang dipakai penulis adalah data pelengkap yang berkaitan pendidikan karakter dengan teori pendidikan Fiqih yang pada umumnya diperoleh dari berbagai fakar ahli dibidangnya dan para pemikir- pemikir Islam.

Adapun untuk keperluan analisis data digunakan berbagai metode analisa data sebagai berikut: (a) Metode Deskriptik, dimana langkah-langkah yang dilakukan dalam rangka representasi obyektif tentang realitas yang terdapat di dalam masalah yang diselidiki. Atau dapat diartikan sebagai metode yang digunakan untuk mendeskripsikan segala hal yang berkaitan dengan pokok-pokok permasalahan, dan mensistematisir sedemikian rupa. Selanjutnya dengan keyakinan tertentu diambillah kesimpulan umum dari bahan-bahan tentang obyek permasalahannya. Dengan demikian kajian dan metode analisis dalam penelitian tesis ini tidaklah terhenti pada taraf deskripsi saja, tetapi dilakukan sampai pada taraf inferensial. (b) Metode Analitik, digunakan untuk menelaah atau mengkaji pemikiran fuqaha', baik yang dikemukakan oleh ulama' sufi ilmuan lainnya. Pertama, cara yang 
digunakan adalah analisis isi (content analysis), yaitu menganalisis isi dari berbagai tulisan atau karya pemikiran yang terkait dengan pendidikan fiqih, terutama yang dikemukakan oleh al-Ghazali, al-Jailani, al-Mawardi, al- Kurdi dan al- Ghulayini. Kedua, cara yang digunakan adalah penafsiran gramatikal (grammatical interpretation) yaitu penafsiran segi kebahasaan, jenis bahasa, struktur dan makna yang tepat dalam kalimat dan stylenya; prosa, puisi, narasi. Penafsiran ini terkadang disebut juga dengan penafsiran obyektif.

\section{HASIL PENELITIAN DAN PEMBAHASAN}

\section{Fiqih Membentuk Karakter Islami Peserta Didik di SD/MI}

Karakter memiliki arti mengukir. Karakter diartikan sebagai sifat-sifat kejiwaan, akhlak, atau budi pekerti yang membedakan seseorang dari yang lain. ${ }^{4}$ Karakter juga bisa diartikan tabiat, yaitu perangai atau perbuatan yang selalu dilakukan atau kebiasaan. Karakter bermakna watak, sifat batin manusia yang mempengaruhi segenap pikiran, tingkah laku dan kepribadian.

Ada beberapa istilah yang menyebut tentang manusia diadalam al-Qur'an antara lain, al- Insan ( QS.al-Insan : 1), al- Bashar ( QS. Al-Kahfi : 110), al- Nas (QS.al-Nas : 1) bani adam ( al- Isra: 70 ). Berbagai rumusan didalam al-Qur'an termaktub bahwa manusia adalah makhluk dengan berbagai karakter. Ada dua kecendrungan karakter yang saling berseberangan, yaitu karakter baik dan karakter buruk. Allah swt. menyatakan:

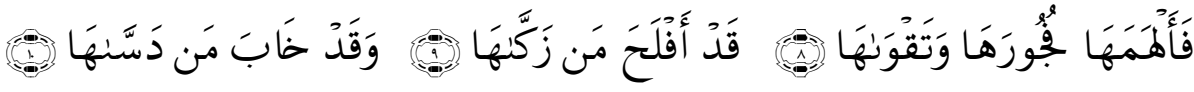

$$
\begin{aligned}
& \text { " Maka Allah mengilhamkan kepada jiwa itu (jalan) kefasikan dan }
\end{aligned}
$$

\section{Pembentukan Karakter Islami}

Ciri khas karakter Islami adalah terwujudnya prilaku mulia sesuai dengan tuntunan Allah swt. yang dikenal dengan akhlak al-karimah. Akhlak al-Karimah yang menghiasi seseorang mampu mampu mengendalikan dari keinginan- keinginan yang bersifat negatif dan sebaliknya dapat mengarahkan atau memotivasi seseorang kearah kebaikan. Untuk menuju kebaikan tersebut tentu bukan suatu yang mudah. Oleh karena itu perlu usaha sungguh untuk menumbuhkembangkannya. Proses pembentukan karakter ada dua cara yaitu :

\footnotetext{
4 Kamus Besar Bahasa Indonesia.

${ }^{5}$ Al-Qur'an (91) :8-10
} 
Pertama, Proses secara individual, hal ini dapat dilakukan melalui tiga macam pendidikan: (a) Pranatal Education ( Pendidikan Pralahir), Proses pendidikan ini dapat dilakukan secara tidak langsung. (b) Education by Another ( Pendidikan dengan orang lain), Proses pendidikan ini dilakukan secara langsung oleh orang lain. (c) Self Education Pendidikan Mandiri), Proses ini dilakukan melalui aktifitas pribadi tanpa bantuan orang lain, seperti membaca kitab atau buku, majalah dan sebagainya, atau melakukan riset untuk menemukan hakikat segala sesuatu bahkan lewat perenungan untuk menemukan jatidiri tanpa bantuan orang lain.

Kedua, Proses pembentukan karakter secara massal. Proses ini dapat dilakukan secara bersama dan menjadi tanggungjawab bersama Dalam sebuah hadis Rasulullah SAW.. menyatakan:

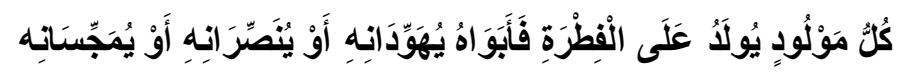

"Setiap anak dilahirkan dalam keadaan fitrah(suci), Kedua orangtuanyalah yang membentuk anak itu menjadi Yahudi, Nasrani dan Majusi,.” 6

pengaruh orang tua dalam bidang ekonomi juga akan memberikan dampak nilai, yakni apakah anak tersebut akan menjadi seorang kapitalis, konsumeris, hedones atau materialis. Dalam hal politik, orang tua juga berperan nyata yakni anak itu akan menjadi adil, bijaksana , ambisius, serakah, diktator, tirani, kejam, dan seterusnya.

Ada beberapa prinsip yang bisa ditekankan dalam pembentukan karakter secara individu maupun komunal antara lain : Prinsip akidah yang bersih ( Salim al-'aqidah), Ibadah yang benar ( sahih al-ibadah ), Etika yang kokok ( matin al-khuluq), Jasmani yang kuat ( qawi al-jism ), Berwawasan Budaya. ( muthaqqaf al-fikr), Mampu memerangi Hawa Nafsu ( Mujahadat li nafsihi ), Pandai Mengatur waktu ( Harisun 'ala waqtihi ), Teratur dalam Urusan-urusannya ( Munadhamun Li Shu'unihi), Berjiwa Enterpreunership ( qadirun 'ala al-kasb), Bermanfaat bagi orang lain dan alam sekitarnya (nafi'un lighairihi )

\section{Fiqih Sebagai Pembentuk Karakter Islami}

Fiqih adalah kodifikasi hukum yang bersumber dari al-Qur'an dan al-Hadis serta Ijtihad 'ulama. Fiqih memiliki ikatan yang erat dengan ilmu-ilmu yang lain seperti; tauhid, tasawuf, sejarah, bahasa, perbandingan mazhab, tafsir dan hadis. Pembentukan karakter tergantung sejauh mana individu mengembangkan dirinya dengan bimbingan petunjuk Allah swt., dalam rangka mengembangkan tugasnya sebagai khalifah di muka bumi serta melaksanakan kewajiban sebagai hamba Allah melakukan pengabdian kepada-Nya.

\footnotetext{
${ }^{6}$ HR: Al-Aswad Ibn Sari' dalam Kitab Mukhtarul Hadis hal:130
} 


\section{Membangun Karakter Islami Peserta Didik}

Secara alami, anak memerlukan pendidikan atau bimbingan dari orang lain yang lebih dewasa dan berpengetahuan.. Allah menjelaskan dalam firman-Nya:

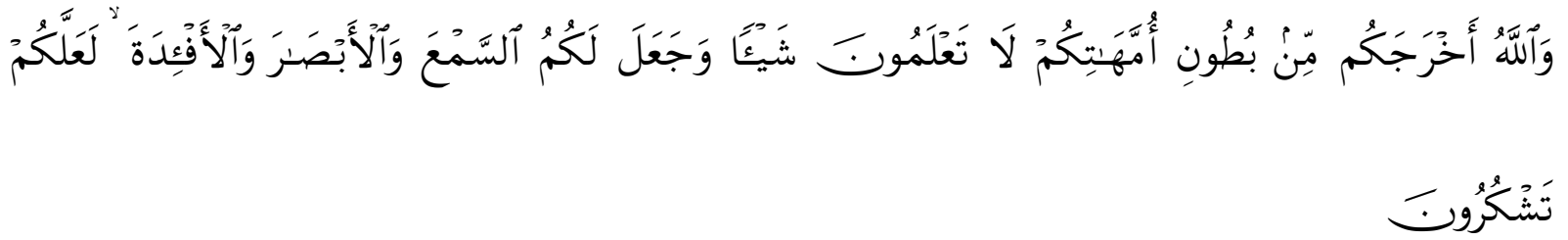

“ Dan Allah mengeluarkan kamu dari perut ibumu dalam Keadaan tidak mengetahui sesuatupun, dan Dia memberi kamu pendengaran, penglihatan dan hati, agar kamu bersyukur." 7

Berdasarkan ayat diatas, bahwa untuk menentukan status manusia sebagaimana mestinya adalah melakukan pendidikan. Keharusan memperoleh pendidikan itu sebenarnya mengandung aspek-aspek sebagai berikut: Aspek Paedagogis , Aspek sosiologis dan cultural, Aspek Tauhid, Aspek fiqih

Akhlak merupakan tabiat manusia yang dapat dilihat dari dua bentuk, yaitu: Tabiat tabiat fitrah, dan Prilaku positip berupa akhlak yang muncul dari perangai yang banyak dipraktekkan dan ditaati, sehingga menjadi bagian dari adat kebiasaan yang terpatri pada dirinya. Seperti pema'af, suka menolong, toleransi dan lain sebagainya. Sedangkan ciri akhlak Islam tidak jauh beda dengan tujuan -tujuan fikih antara lain: Universal ( 'Ammah, bersifat menyeluruh ), Seimbang ( Tawassut = Balance $)$, Sederhana, Realistis, Mudah ( Yusr ), Mengikat. Tetap ( Tathbit).

\section{Kontribusi Nilai-Nilai Fiqih dalam Pembentukan Karakter Islami}

Nilai-nilai dalam Islam mengandung dua kategori arti dilihat dari segi normatif, yaitu baik dan buruk. Sedangkankan dilihat dari segi operatif dalam fiqih terdapat lima kategori yang menjadi prinsip standarisasi prilaku manusia yaitu: Wajib, yaitu bila dikerjakan orang akan mendapat pahala dan bila ditinggalkan akan mendapat dosa.; Sunnat, yaitu bila dikerjakan orang akan mendapat pahala dan bila ditinggalkan tidak mendapat dosa; Mubah, yaitu bila dikerjakan maupun ditinggalkan pelakunya tidak diberikan sanksi apapun baik pahala maupun dosa.; Makruh, yaitu bila dikerjakan tidak diberikan dosa, namun perbuatan

\footnotetext{
${ }^{7}$ Al-Qur'an (16):78
} 
tersebut dibenci oleh Allah. Dan bila ditinggalkan akan mendapatkan pahala; Haram, yaitu bila dikerjakan akan mendapat dosa dan bila ditinggalkan akan mendapatkan pahala. ${ }^{8}$

Nilai- nilai spiritual fiqih memiliki kaitan yang erat dengan amaliah sehari khususnya yang menyangkut ibadah kepada Allah. Nilai fiqih juga menjadi ruh (spirit) untuk menuju keridaan Allah. Spiritual fiqih digali dari dua cara yaitu; Melalui iman dan takwa dan Melalui ibadah

Membangun karakter Islami berangkat dari dua cara berkaitan erat dengan dasar akhlaki. Konsep iman takwa merupakan fondasi dari segala aktivitas sedangkan konsep ibadah berpusat pada prinsip dasar yang penting bahwa manusia diciptakan sebagai pemegang mandat dari Allah swt. yang memikul risalah dan menjalankan syariat-Nya.

\section{KESIMPULAN DAN SARAN}

\section{Kesimpulan}

Berdasarkan uraian-uraian terdahulu terhadap penelitian dan pembahasan tentang Kontribusi Nilai-nilai Fiqih Dalam Membangun Karakter Peserta Didik dapat dikemukakan kesimpulan dan saran sebagai berikut : Pertama, Tujuan pendidikan fiqih adalah mengarah dan mengantarkan peserta didik untuk dapat memahami pokok-pokok hukum Islam dan cara pelaksanaanya untuk diaplikasikan dalam kehidupan sehingga menjadi muslim yang selalu taat menjalankan syariat Islam secara kaffah (sempurna). Sebagai pedoman hidup individual, hidup berkeluarga, hidup bermasyarakat berbangsa dan bernegara demi meraih meraih rida Allah swt.

Kedua, Nilai spritual fiqih adalah suatu pola normatif yang menentukan tingkah laku yang diinginkan bagi suatu sistem yang ada kaitannya dengan lingkungan sekitar tanpa membedakan fungsi - fungsi bagian- bagiannya. Nilai mendorong orang untuk berkompetesi dalam kebaikan sekaligus mencegah untuk melakukan kejahatan. Nilai-nilai spiritual ( ruhiyat ) memiliki dorongan yang kuat uuntuk beribadah kepada Allah swt, disamping memotivasi jiwa dan raga untuk selalu dekat kepada Tuhan. Nilai- nilai spiritual juga mampu mendorong pelakunya untuk melakukan amal saleh dan meninggalkan hal-hal yang mungkar. Ungkapan yang lain spirit adalah upaya beribadah dan bertaqarrub dengan tulus ikhlas mengharap ridla Allah swt.

Ketiga, Strategi pembelajaran fiqih adalah cara-cara yang digunakan pendidik untuk memilih kegiatan belajar yang dipergunakan selama proses belajar mengajar. Strategi

\footnotetext{
${ }^{8}$ Sulaiaman Rasyid dalam Fiqh Islam hal:1
} 
merupakan pengetahuan atau seni yang menggunakan semua faktor untuk mengamankan sasaran pembelajaran yang hendak dicapai melalui perencanaan dan pengarahan dalam operasionalisasi sesuai dengan situasi dan kondisi medan pendidikan. Strategi pembelajran fiqih bersifat aktif, aplikatif dan tergantung situasi dan kondisi materi yang semakin fluktuatif sesuai perkembangan zaman.

Keempat, Membangun karakter didalam ajaran Islam selalu dimulai dari pribadi, sejak bayi didalam kandungan, ketika dilahirkan, dan sampai mendekati ajal bertemu dengan tuhannya. Karena peserta didik adalah orang yang berada pada fase pertumbuhan dan perkembangan baik fisik maupun psikis. Dan dibekali dengan aturan-aturan dalam fiqih yang mengatur hukum hubungan dengan Tuhan dan hukum yang berkaitan bergaulan sosial kemasyarakatan sehari- hari. Hukum-hukum tersebut memiliki ganjaran apabila dilaksanakan dan mempunyai sanksi jika dilanggar. Juga didalamnya terdapat perlindungan dan penghormatan hak-hak pribadi, sosial dan masyarakat.

\section{Saran-saran}

Sebagai implikasi dari hasil penelitian yang diperoleh beberapa hal yang dapat dikembangkan lebih lanjut sebagai saran dalam penelitian ini, antara lain : Pertama, Kementerian Pendidikan Nasional dan Kementerian Agama selaku pemegang kebijakan pendidikan di Indonesia agar menyusun kurikulum pendidikan berbasis moralitas dan berkarakter. Kedua, Kepada penegak hukum kepolisian dan kejaksaan, agar menindak setiap pelaku yang melanggar hukum, sesuai dengan tingkat kesalahan yang dilanggarnya. Mengingat hukum kita sekarang ini masih menggunakan hukum atau undang- undang warisan bangsa luar atau yang berasal dari Eropa. Sesekali tengoklah hukum fiqih Islam yang mayoritas dianut oleh orang Indonesia. Hukum fiqih tersebut memiliki kredibilitas dan kelenturan yang sesui dengan keadilan dan kemanusiaan.

Ketiga, Kepada Kepala sekolah dan guru, untuk terus membina karakter peserta didiknya di sekolah dengan menerapkan nilai-nilai agama yang bersumber dari al-Qur'an maupun al-Sunnah. Juga menerapkan nilai-nilai luhur bangsa ini sebagai pijakan dalam bertindak. Keempat, Kepada semua orang tua, agar memperhatikan perkembangan kepribadian dan karakter putra-putrinya sambil menanamkan sikap dan prilaku positif secara intens dan bertanggung jawab.

\section{Daftar Pustaka}

Ali, Mohammad. Ilmu dan Aplikasi Pendidikan. Bandung : UPI, 2006

Arifin,Muzayyin. Filsafat Pendidikan Islam. Jakarta : Bumi Aksara, 2009 
Ilmu Pendidikan Islam Tinjauan Teoritis dan Praktis. Jakarta : Bumi Aksara,2009

Arikunto, Suharsimi. Prosedur Penelitian Suatu Pendekatan Praktek. Jakarta: Rineka Cipta, 2002

Aly, Hery Noer. Watak Pendidikan Islam. Jakarta : Priska Agung Insani,2008 . Pendidikan Islam Kini \& Mendatang. Jakarta: Triasco, 2007

Bahreisy, Husein. Ajaran-ajaran Akhlak Imam al-Ghazali. Surabaya: al-Ikhlas, 1990

Daradjat, Zakiah. Ilmu Pendidikan Islam. Jakarta : Bumi Aksara, 2009

D.Marimba, Ahmad. Pengantar Filsafat Pendidikan Islam. Bandung : al-Ma'arif,1977

Daud Ali, Muhammad. Hukum Islam. Jakarta: Raja GrafindoPersada, 2007

Daudy, Ahamd. Kuliah Filsafat Islam. Jakarta : Bulan Bintang, 1986

Hadi, Sutrisno. Metodologi Research I. Yogyakarta : Fakultas Psikologi Universitas Gajah Mada, 1987

Hasan Langgulung, Beberapa Pemikiran Tentang Pendidikan Islam. Bandung: al-Ma'arif, 1996

Hasan, M. Iqbal. Pokok- pokok Materi Metodologi Penelitian dan Aplikasinya. Jakarta : Ghalia Indonesia, 2002

Hidayatullah, Furqan. Guru Sejati : Membangun Insan Berkarakter Kuat dan Cerdas. Surakarta: Yuma Pustaka, 2009

Ibnu Rushd, Bidayat al-Mujtahid. Beirut : Dar al- Fikr, 1993

Ihsan, Hamdani, Filsafat Pendidikan Islam. Bandung : Pustaka Setia, 2007

Imam al-Ghazali, Ihya' 'Ulum al-Din. Semarang: Toha Putra, 1996

Kartono, Kartini. Pengantar Ilmu Pendidikan Teoritis. Bandung: Mandar Maju, 1997

Khalid, Amr. Spirit al-Qur'an Kunci Kunci Menuju Kebahagiaan Abadi. Yogyakarta : Darul Hikmah, 2008

al- Kurdi, Muhammad Amin. Tanwir al- Qulub. Surabaya: al- Haramain, 2006

Kaelan, Metode Penelitian Agama Kualitatif Interdisipliner. Yogyakarta: Paradigma, 2010

Saleh Abdullah, Abdurrahman, Teori-Teori Pendidikan Berdasarkan al-Qur'an. Jakarta: Rineka Cipta, 1999 